\title{
Physical Properties of Copper Oxide Thin Films Prepared by Sol-Gel Spin-Coating Method
}

\author{
Mehdi Dhaouadi ${ }^{1,2, ~ *}$, Mohamed Jlassi ${ }^{3}$, Imen Sta ${ }^{1}$, Islem Ben Miled ${ }^{1,2}$, George Mousdis ${ }^{4}$, \\ Michael Kompitsas ${ }^{4}$, Wissem Dimassi ${ }^{1}$ \\ ${ }^{1}$ Department of Physics, Photovoltaic Laboratory, Research and Technology Centre of Energy, Borj-Cedria Science and Technology Park, \\ Hammam-Lif, Tunisia \\ ${ }^{2}$ Department of Physics, Faculty of Sciences of Bizerte, Zarzouna, Tunisia \\ ${ }^{3}$ Department of Physics, Higher School of Science and Technology of Design, University of Manouba, Tunis, Tunisia \\ ${ }^{4}$ Department of Physics, National Hellenic Research Foundation, Theoretical and Physical Chemistry Institute, Athens, Greece
}

Email address:

mehddhaw@gmail.com (M. Dhaouadi)

${ }^{*}$ Corresponding author

\section{To cite this article:}

Mehdi Dhaouadi, Mohamed Jlassi, Imen Sta, Islem Ben Miled, George Mousdis, Michael Kompitsas, Wissem Dimassi. Physical Properties of Copper Oxide Thin Films Prepared by Sol-Gel Spin-Coating Method. American Journal of Physics and Applications.

Vol. 6, No. 2, 2018, pp. 43-50. doi: 10.11648/j.ajpa.20180602.13

Received: November 26, 2017; Accepted: December 5, 2017; Published: January 29, 2018

\begin{abstract}
In this study, copper oxide thin films prepared by the sol-gel method, have been deposed onto glass substrates by the spin coating technique. Our target was to study their properties and improve them for photovoltaic use. These properties were optimized by varying the temperature annealing and the molar concentration of the precursor solutions. The effects of the annealing temperature on the structural and optical properties of the thin films are studied. It was found that the film treated at $550^{\circ} \mathrm{C}$ shows a higher absorbance. Then by using this optimized temperature, $\mathrm{CuO}$ thin films of various molar concentrations, were deposited at the same experimental conditions. The structural analysis by X-ray diffraction (XRD) shows that all the samples are polycrystalline with monoclinic crystal structure. Raman scattering measurements of all thin films confirms the structure of $\mathrm{CuO}$. The optical properties of the films were characterized by UV-Visible-NIR spectrophotometry, which shows that the films show high absorbance in the visible region. Their optical band gap decreases from 3.68 to $2.44 \mathrm{eV}$ when the molar concentration of precursor solutions increases from 0.1 to $0.5 \mathrm{M}$. The electrical measurements show that the resistivity of the films varies slightly from $84 \Omega \mathrm{cm}$ to $124 \Omega \mathrm{cm}$ as the molar concentration increases.
\end{abstract}

Keywords: Sol-Gel, Spin-Coating, Copper Oxide, Thin Films, Physical Properties

\section{Introduction}

$\mathrm{CuO}$ thin films have attracted much attention last years due to their electrical and optical properties [1-3]. Moreover, to lower manufacturing cost and no toxicity.

The main process to reduce the manufacturing cost is the replacement of the silicon [4] In fact, the band gap of $\mathrm{CuO}$ is close to that of $\mathrm{Si}[5]$ and GaAs [6], matching the solar spectrum more closely; therefore, the achievable solar conversion efficiency could be up to $33 \%$ for a single junction solar cell with a band gap close to $1.4 \mathrm{eV}[7,8]$.

A number of reports [9-12] have been focused largely on its catalytic and gas sensitive properties; however, photovoltaic cells based on $\mathrm{CuO}$ received more attention due to their excellent photovoltaic properties $[13,14]$ and ease of fabrication $[15,16]$. Electrical and optical properties of $\mathrm{CuO}$ thin film depend strongly on its structure; hence, they are related to its fabricating conditions. Thus, in order to achieve higher efficiency of solar cell based on $\mathrm{CuO}$ thin film, it is important first to investigate their intrinsic relationship.

Copper oxide appears with 2 oxidation numbers $(+1,+2)$, namely, cupric oxide $(\mathrm{CuO})$ and cuprous oxide $\left(\mathrm{Cu}_{2} \mathrm{O}\right)$, both of them are p-type semiconductors with optical direct band gaps at the range of $1.3-3.7 \mathrm{eV}$ for $\mathrm{CuO}$ and $1.8-2.5$. eV for $\mathrm{Cu}_{2} \mathrm{O}$ [17 - 19]. The cupric oxide possesses a direct band gap starting from $1.3 \mathrm{eV}$, which is ideal for an absorber material 
to be used in solar cell applications $[20,21]$. $\mathrm{CuO}$ thin films have been prepared using various techniques such as sol gel [22], wet-chemical synthesis [23], magnetron sputtering [24], pulsed laser deposition [17], molecular beam epitaxy [25], electro deposition [26] etc. Among these, the sol-gel is especially suitable, since it has proved to be a simple and inexpensive method, particularly useful for large area applications. This method has also the advantage that the final properties of the films can be tailored by the type and concentration of precursors as well as the annealing temperatures [27].

In this study, the fabrication and characterization of multi layer $\mathrm{CuO}$ films (up to four layers) on glass substrates are presented. The films were annealed in different temperatures to find the optimum annealing temperature for the excellent physical properties. By using this optimum annealing temperature, $\mathrm{CuO}$ thin films were prepared using different molar concentration of precursor at the starting solution. A detailed parametric study concerning the effect of annealing temperature and $\mathrm{Cu}$ molar concentration on the structural, optical and electrical properties of $\mathrm{CuO}$ thin films has been carried out. This work focuses at the amelioration of the $\mathrm{CuO}$ thin films properties with a view to be used as an absorbing material in photovoltaic devices.

\section{Experimental Procedures}

$\mathrm{CuO}$ thin films were prepared by the sol-gel method. First, the copper precursor solution was prepared using, copper (II) acetate $\left[\left(\mathrm{CH}_{3} \mathrm{COO}\right)_{2} \mathrm{Cu} / \mathrm{H}_{2} \mathrm{O}\right](98 \%$, Sigma Aldrich), 2methoxyethanol $\left[\mathrm{C}_{3} \mathrm{H}_{8} \mathrm{O}_{2}\right]$ ( $99.8 \%$, Sigma Aldrich), and diethanolamine $\left[\mathrm{NH}\left(\mathrm{CH}_{2} \mathrm{CH}_{2} \mathrm{OH}\right)_{2}\right](\mathrm{MEA} ; 99 \%$, Merck) as the solute, solvent, and solution stabilizer, respectively.

Copper (II) acetate was first added in 2-methoxyethanol to obtain a final concentration of $0.5 \mathrm{M}$. After $15 \mathrm{~min}$ of stirring at room temperature, the hot plate temperature was ramped up to $80^{\circ} \mathrm{C}$ and the MEA was added drop by drop and the mixture was stirred for $1 \mathrm{~h}$ at $80^{\circ} \mathrm{C}$ to obtain a transparent and homogenous solution.

Before deposition, glass substrates were successively cleaned with acetone, ethanol, and deionized water. All $\mathrm{CuO}$ thin films were coated onto glass substrates at a speed of $4000 \mathrm{rpm}$ for $30 \mathrm{~s}$ and dried immediately on a hot plate at $250^{\circ} \mathrm{C}$. This procedure was repeated 4 times and at the end the samples were annealed at various temperature 350,450 and $550^{\circ} \mathrm{C}$ for $1 \mathrm{~h}$ under air. Using the same procedure samples with copper (II) acetate concentrations of 0.1 and 0.3 $\mathrm{M}$ in the precursor solution were prepared and annealed at $550^{\circ} \mathrm{C}$ for $1 \mathrm{~h}$ under air.

The crystallographic structure of the films was studied by X-ray diffraction (XRD), using a Bruker D 8 advance, X-ray diffractometer with $\mathrm{Cu} K \alpha$ radiation $\left(\lambda_{\mathrm{CuK} \alpha}=1.5418 \AA\right)$ radiation, for $2 \Theta$ values in the range of $20-70^{\circ}$. The thickness of the thin films was measured using a KLA Tencor Alpha-step IQ surface profilometer with an accuracy of \pm 1 nm. Raman spectroscopy measurements were carried out using a Raman spectrometer (RENISHAW RAMASCOPE 2000) with a $632 \mathrm{~nm}$ line of $\mathrm{HeNe}$ laser. The optical transmittance of the films was measured by a UV-Vis-NIR spectrophotometer in the wavelength range from 300 to 1500 $\mathrm{nm}$. The electrical resistivity was measured in a four point probe configuration (by a Van der Pauw method) [28]. All measurements were carried out at room temperature.

\section{Results and Discussions}

\subsection{Effect of Annealing Temperature on Physical Properties}

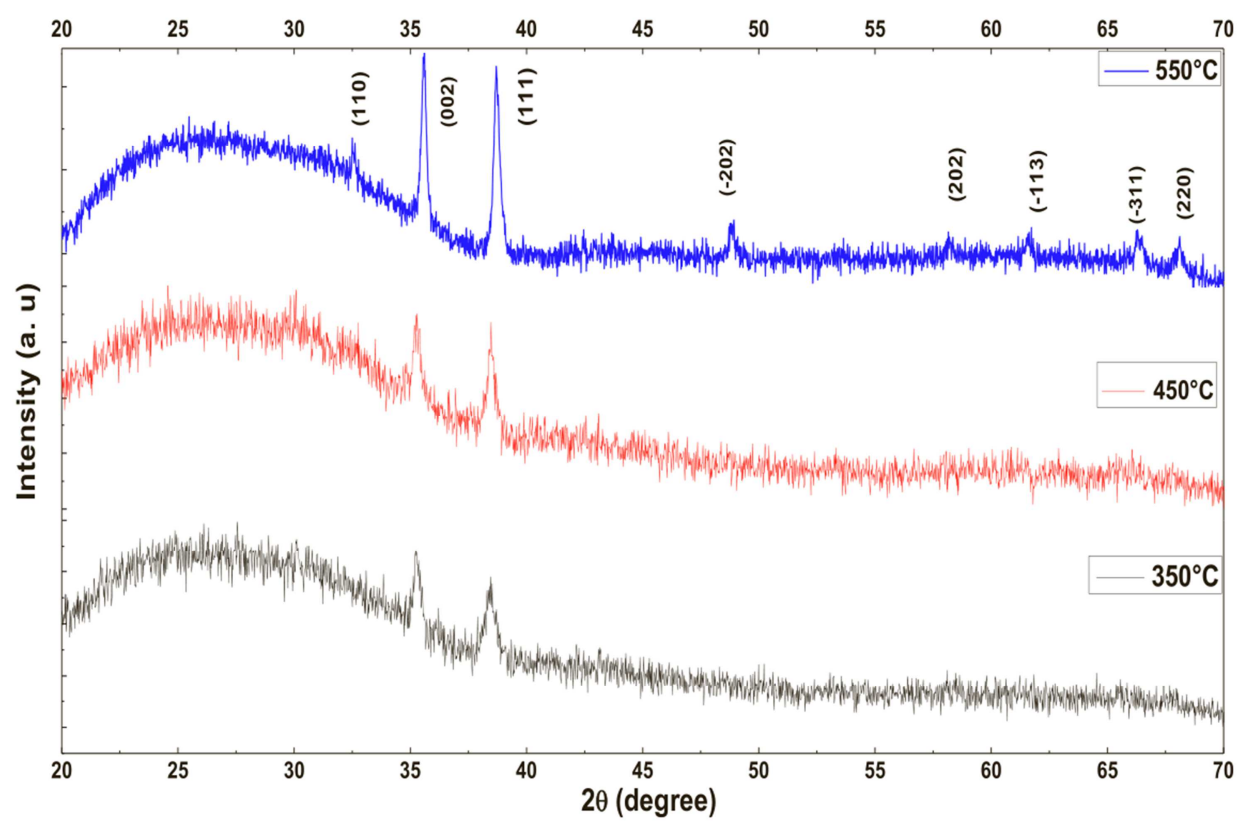

Figure 1. X-ray diffraction patterns of $\mathrm{CuO}$ thin films for different annealing temperatures. 
XRD analysis was carried out to investigate the structural properties of $\mathrm{CuO}$ thin films deposited on glass substrates and post annealing temperatures $350,450,550^{\circ} \mathrm{C}$ for $1 \mathrm{~h}$. Figure 1 shows XRD patterns of $\mathrm{CuO}$ thin films with different annealing treatment and $0.5 \mathrm{M} \mathrm{Cu}{ }^{2+}$ initial concentration. The XRD patterns show that all annealed films have polycrystalline structures. The obtained XRD patterns of all samples matched well with the space group C2/c according to JCPDS (No. 01-089-2529) of the monoclinic $\mathrm{CuO}$ structure and tenorite phase. For lower annealing temperature of $350^{\circ} \mathrm{C}$, the corresponding pattern shows two peaks at around 35.55 and $38.73^{\circ} 2 \theta$ values, assigned to (002), (111) crystallographic plane, respectively. The intensity of these peaks is increased by increasing the annealing temperature to $450^{\circ} \mathrm{C}$. For the higher annealing temperature of $550^{\circ} \mathrm{C}$, a strong orientation along (002) and (111) is observed. Other peaks, such as (110), (-202), (202), $(-113),(-311)$ and (220) are also observed, but their intensities are very small compared to the (002) and (111) peaks. From this result, it can be noted that the amorphous phase is reduced when the annealing temperature is increased. There is no significant difference between the two high intensity peaks along (002) and (111) for the different temperature. To determine the preferential orientation in $\mathrm{CuO}$ films, the texture coefficient was calculated from the XRD data, using the well-known formula [29]

$$
\mathrm{T}_{\mathrm{c}}(\mathrm{hkl})=\frac{I(h k l)}{I_{0}(h k l)}\left[\frac{1}{n} \sum_{i=1}^{n} \frac{I(h k l)}{I_{0}(h k l)}\right]^{-1}
$$

where, $\mathrm{I}_{0}(\mathrm{hkl})$ represents the intensity of reference diffraction pattern (JCPDS card no. 01-089-2529), I (hkl) is the measured intensity of the (h k l) reflection and ' $n$ ' is the number of reflections observed. The texture coefficient $T_{C}$ (hkl) measures the relative degree of preferred orientation among crystal planes. Figure 2 shows $T_{c}$ (hkl) values corresponding to (002) and (111) reflections for samples annealed under different temperatures. Values of $0 \leq \mathrm{T}_{\mathrm{C}}(\mathrm{h} \mathrm{k}$ 1) $\leq 1$ indicate the lack of grain oriented in the corresponding direction. As can be seen, with increasing temperature to $550^{\circ} \mathrm{C}$, the texture coefficient increases slightly, indicating the increase of crystallization of (002) and (111) direction. Moreover, the Tc of (002) plane is higher than the Tc of (111) plane. It is evident that the $\mathrm{CuO}$ films elaborated at $550^{\circ} \mathrm{C}$ have the best crystallinity. These results are in accordance with the results of previous works. [30]. This improvement can be attributed to the coalescences of grains at higher annealing temperature which is confirmed by the decreasing of the full width at half maximum of peaks in the XRD patterns.

The average thickness is measured with surface profilometer and the crystallite size of the nanostructured $\mathrm{CuO}$ films was calculated using the Scherrer formula as follows [31]

$$
D=\frac{k \lambda}{\beta \cos \theta}
$$

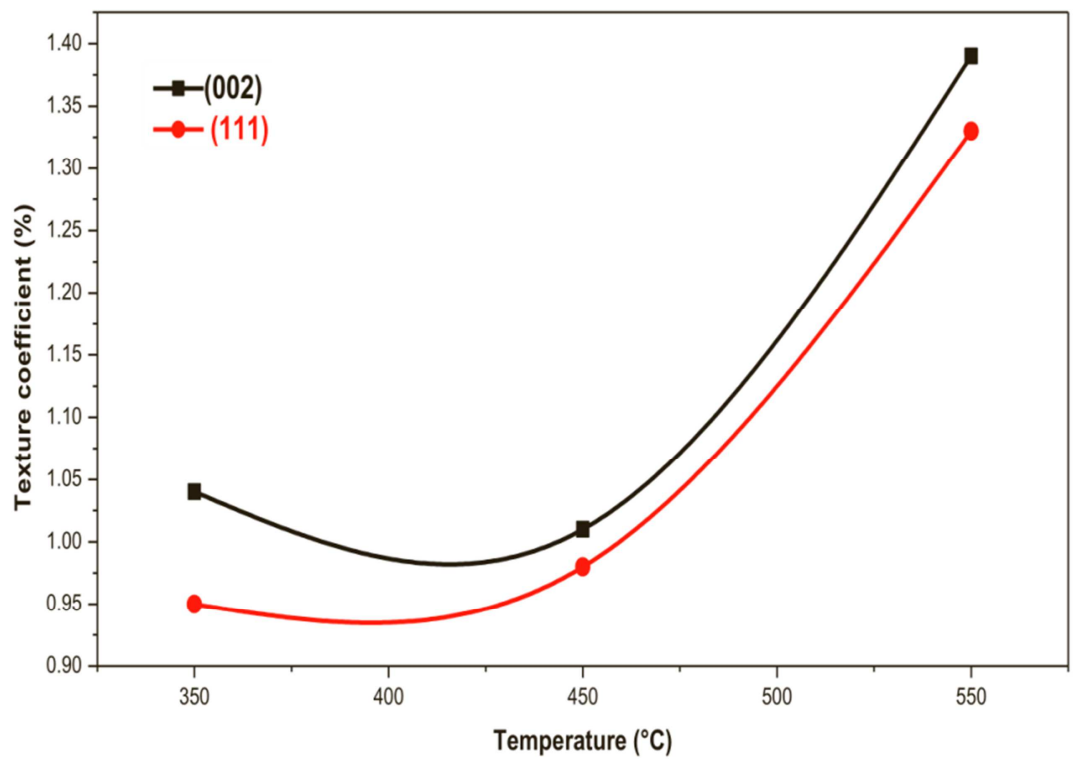

Figure 2. Variation of the texture coefficient for the direction (002) and (111) as a function of annealing temperature.

Table 1 summarizes the average thickness and the estimated average crystallite size of all samples at different annealing temperature. The crystallite size of $\mathrm{CuO}$ is found to increase from 16 to $32 \mathrm{~nm}$, when the annealing temperature increases from 350 to $550^{\circ} \mathrm{C}$. This can be explained by the merging process induced from thermal annealing [32]. The average thickness values vary from $136 \mathrm{~nm}$ to $252 \mathrm{~nm}$. It can be seen that when the annealing temperature increase, thickness of samples also increases. This result is in accord with Ghorannevis et al [33]. It is clear from this results that the best crystallization was obtained for the $550^{\circ} \mathrm{C}$ annealing temperature, this result is in good agreement with Akaltun [34]. 
Table 1. Values of crystallite sizes, average thickness and optical energy gap at different annealing temperatures.

\begin{tabular}{llll}
\hline Temperature $^{\circ} \mathbf{C}$ & Crystallite size (nm) & Average thickness (nm) & Energy gap (eV) \\
\hline 350 & 16 & 136 & 3.5 \\
450 & 18 & 165 & 2.5 \\
550 & 32 & 252 & 2.44 \\
\hline
\end{tabular}

In order to complete the structural analysis of $\mathrm{CuO}$ thin films, Raman spectra were carried out to verify the phases present. $\mathrm{CuO}$ crystallizes in a monoclinic lattice with four formula units in the crystallographic primitive cell and belongs to the space group symmetry of $\mathrm{C}_{2 \mathrm{~h}}^{6}$. $\mathrm{CuO}$ has 12 phonon branches because there are four atoms in the primitive cell:

$$
\Gamma_{\text {vibr }}=A_{g}+2 B_{g}+4 A_{u}+5 B_{u}
$$

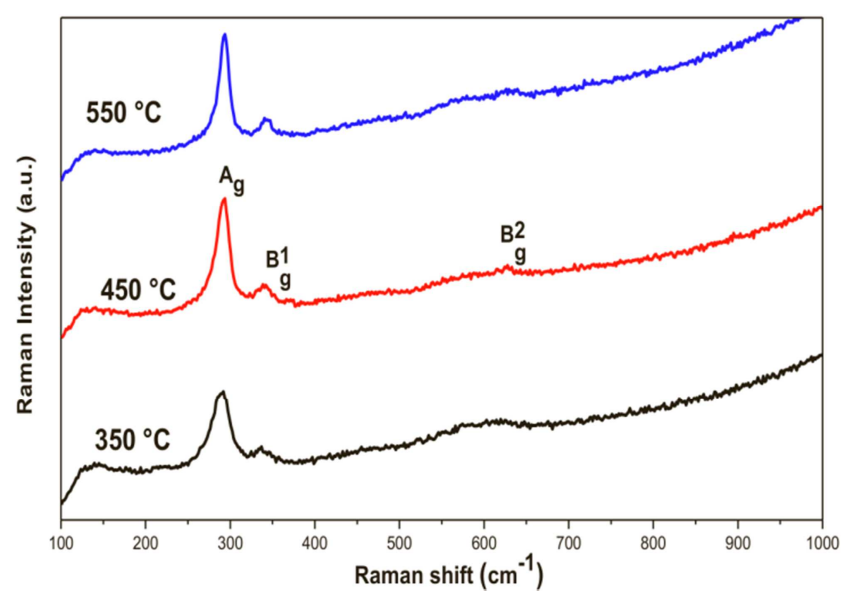

Figure 3. Raman spectra of $\mathrm{CuO}$ thin films at different annealing temperatures.

Generally, there are three acoustic modes $(\mathrm{Au}+2 \mathrm{Bu})$, six infrared active modes $(3 \mathrm{Au}+3 \mathrm{Bu})$ and three Raman active modes $(\mathrm{Ag}+2 \mathrm{Bg})$ [35]. For annealing temperatures from $350^{\circ} \mathrm{C}$ to $550^{\circ} \mathrm{C}$, the Raman scattering revealed the presence of mixed Raman active modes. As can be seen in Figure 3, the spectrum exhibits three main phonon modes $\mathrm{Ag}$ and $2 \mathrm{Bg}$ located at 293, 339 and $624 \mathrm{~cm}^{-1}$, respectively. This result confirms the presence of a single phase $\mathrm{CuO}$ with monoclinic structure [36].

Figure 4 shows the effect of annealing temperature in the range of $350-550{ }^{\circ} \mathrm{C}$ on the optical transmittance of $\mathrm{CuO}$ thin films. The film transparency decreases with increasing temperature. This behavior is due to the increase in thicknesses of $\mathrm{CuO}$ thin films. However, it is clear that $\mathrm{CuO}$ films exhibit a relatively high absorption in the visible region ranging from 400 to $800 \mathrm{~nm}$, indicating suitability of the material for the solar cell applications. As can be seen, this variation is in same range reported in the literature [37, 38]. The lower IR transmittance profile of these thin films may also be due to the scattering effect of light through the optically anisotropic monoclinic structure [39]. It is observed that $\mathrm{CuO}$ film annealing at $550^{\circ} \mathrm{C}$ absorbs strongly throughout the visible spectrum with a slight transparency. The direct band gap of $\mathrm{CuO}$ films was determined by employing the Tauc model [40]:

$$
\alpha=\frac{A\left(h \gamma-E_{g}\right)^{1 / 2}}{h \gamma}
$$

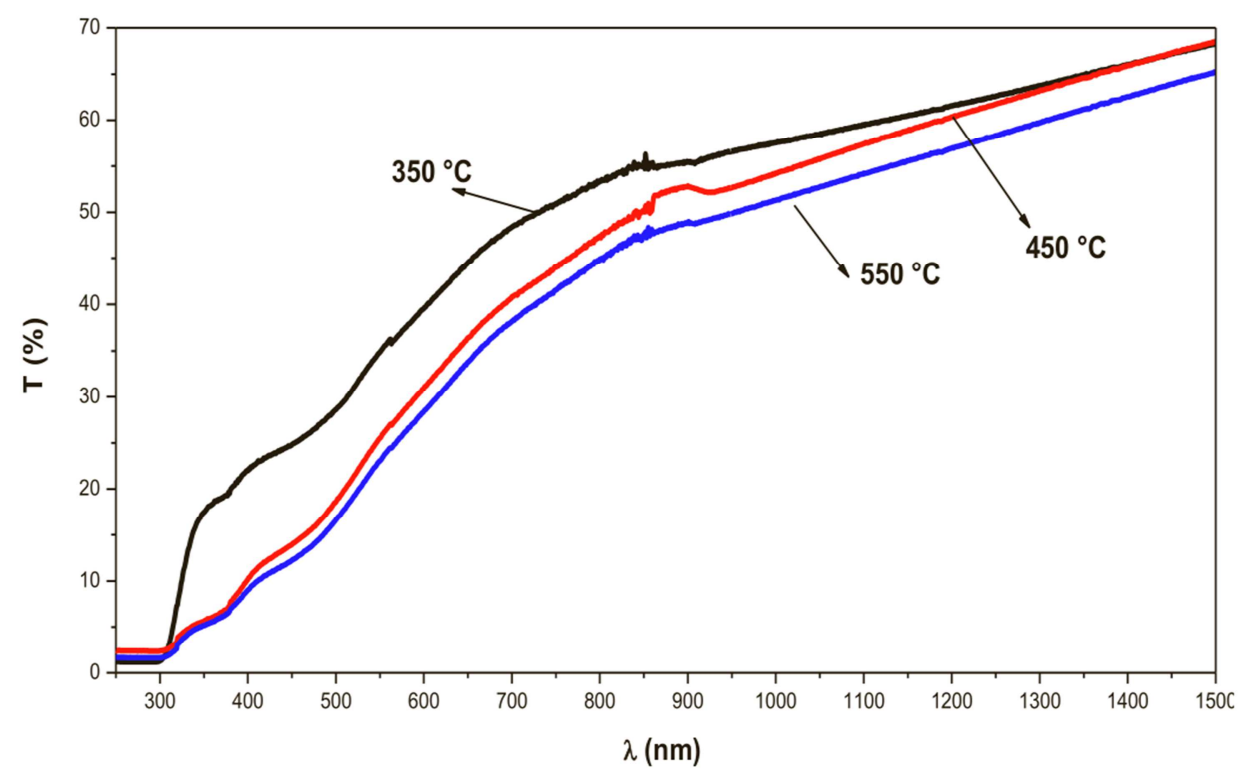

Figure 4. Optical transmission spectra for $\mathrm{CuO}$ thin films annealed at different annealing temperatures.

where $\alpha$ is the absorption coefficient of the film, $h \gamma$ is the photon energy, $\mathrm{A}$ is a constant and $\mathrm{Eg}$ the optical band gap energy.

Table 1 lists the band gap values for all samples, which show a decrease of the band gap from 3.5 to $2.44 \mathrm{eV}$ with the annealing temperature, which is related to the quality of the film due to the annealing out of the structural defects [30] and 
to the increase crystallites size. Our results corroborate those found in the literature [18, 41]. Dattarya et al [30] ascribed this shift in energy band gap, e.g., to the increase in crystallites size and the reduction of the amorphous phase for the annealing $\mathrm{CuO}$ films. In this case, the mean crystallite size increases from $15.8 \mathrm{~nm}$ to $32.2 \mathrm{~nm}$ after annealing from $350^{\circ} \mathrm{C}-550^{\circ} \mathrm{C}$. Therefore, we believed that the amorphous phase is reduced with increasing annealing temperature, since more energy is supplied for crystallite growth, thus resulting in an improvement in crystallinity of the $\mathrm{CuO}$ films. Moreover, it is understood that both the increase in crystallite size and the improvement of the crystallinity are responsible for the band gap decreasing with increase annealing temperature of $\mathrm{CuO}$ films. The annealing temperature of $550^{\circ} \mathrm{C}$ seems to be the best, with best properties studied. Based on the obtained results, the annealing temperature was fixed to $550^{\circ} \mathrm{C}$.

\subsection{Influence of the Precursor Molar Concentration on Copper Oxide Thin Films}

\subsubsection{Structural Characterization}

Figure 5 shows the X-ray diffraction patterns of $\mathrm{CuO}$ thin films with different molar concentrations, $0.1,0.3$ and $0.5 \mathrm{M}$. The X-ray diffraction patterns of $\mathrm{CuO}$ thin films elaborated with $0.1 \mathrm{M}$ show high intensity of picks observed at $2 \theta=$ $35.55^{\circ}$ and $38.73^{\circ}$ corresponds to the (002) and (111) diffraction planes and some small peaks assigned to (110), (202), (202), (-113), (-311) and (220) observed at $2 \theta=32.52$, $48.74,58.30,61.56,66.25$ and $68.13^{\circ}$, respectively. It can be noticed that the XRD pattern has not much altered by increasing in molar concentration. All the apparent atomic plans revel that the deposited films are composed of a single $\mathrm{CuO}$ phase with monoclinic crystal structure. Based on these results from the present study, the sol-gel method combined with the spin-coating technique and optimized deposition parameters yield to only the single tenorite $\mathrm{CuO}$ phase with monoclinic structure at the higher annealing temperature of $550^{\circ} \mathrm{C}$. The $(002)$ and $(111)$ diffraction peaks of $\mathrm{CuO}$ was intensified in the process of increasing the concentration due to the increase in thickness of the film, which is consistent with the results reported by R. Shabu et al. [38].

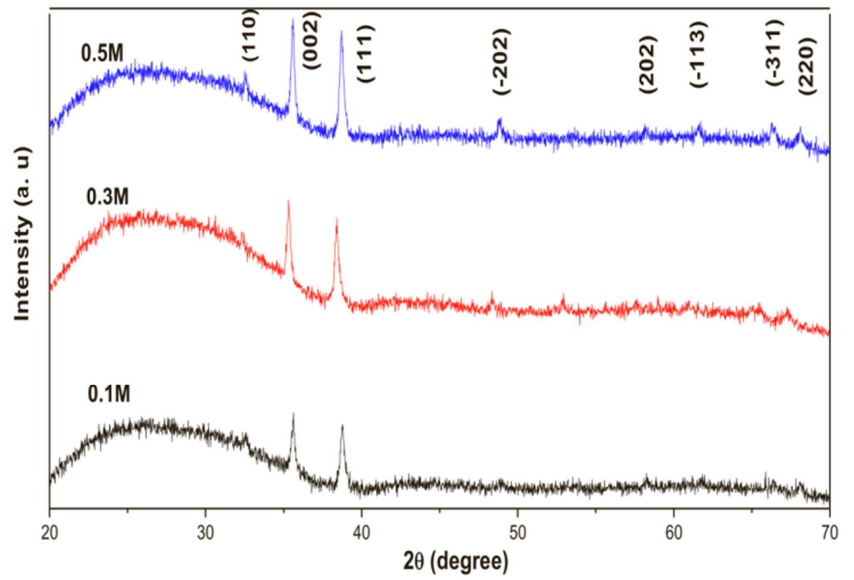

Figure 5. X-ray diffraction pattern $\mathrm{CuO}$ thin film with different precursor molar concentration.
The different texture coefficients $T_{C}(h k l)$ have been calculated from the X-ray data. We have calculated the texture coefficient for the two dominated atomic plan (002) and (111). The $\mathrm{T}_{\mathrm{C}}(\mathrm{hkl})$ values for $0.3 \mathrm{M}$ are lower than 0.1 $\mathrm{M}$ and the $0.5 \mathrm{M}$ are higher than both as shown in Figure 6 . In all the cases, the $T_{c}$ of (002) plane is slightly higher than that of (111) plane.

All films have a polycrystalline nature and the calculated texture coefficient shows that the $\mathrm{CuO}$ films elaborated with precursor concentration equal to $0.5 \mathrm{M}$ have the best crystallinity.

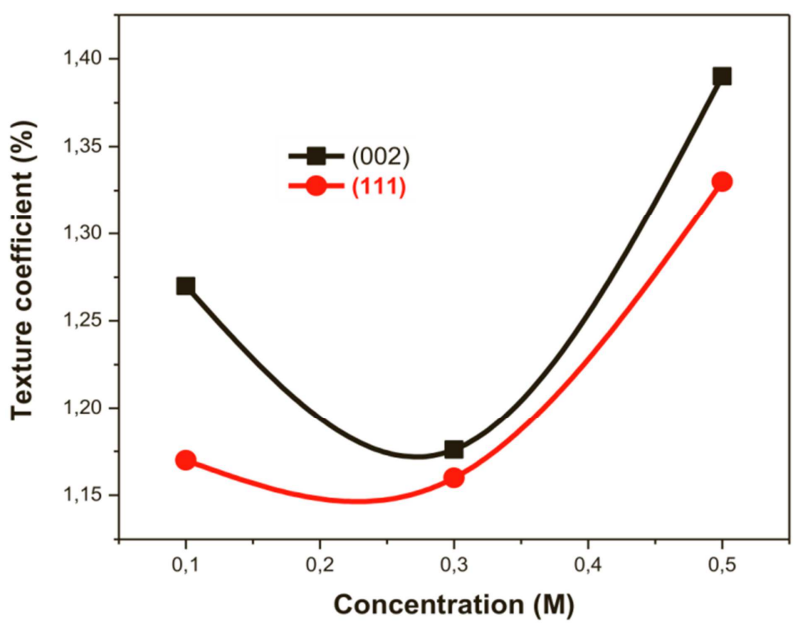

Figure 6. Variation of the texture coefficient for the direction (002) and (111) as a function of precursor molar concentration.

The variations of crystallite size and strain with molar concentration are shown in Figure 7. The average crystallite size deduced from the full width at half the maximum (FWHM) of (200) planes was estimated using Scherrer's relation [29]. The strain $(\varepsilon)$ developed in films due to lattice misfit was evaluated using Eqs [42].

$$
\varepsilon=\frac{\beta \cos \theta}{4}
$$

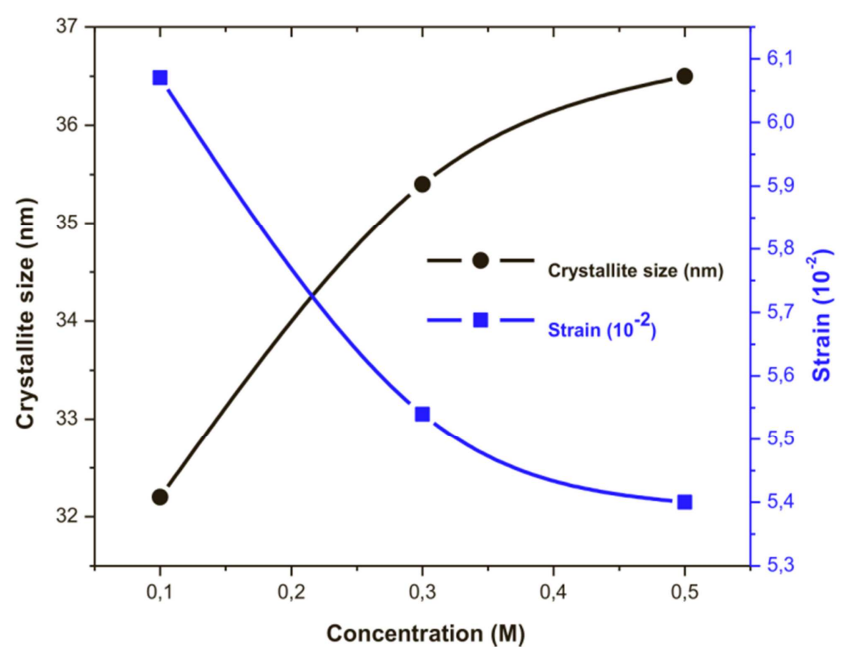

Figure 7. Crystallite size and strain of Cu-oxide thin films as a function of precursor molar concentration.

It is apparent from the figure that crystallites size increase 
with increasing the molar concentration. This variation can be related to the increase in film thicknesses. In addition, the increase in the precursors molarity leads to increase in $\mathrm{Cu}$ concentration which results in a higher condensation of $\mathrm{Cu}$ atoms and faster nucleation in consequence a growth of bigger crystallites. On the other hand, strain decrease with increasing the precursors molarity. From these results, it was confirmed that the fundamental effect of increase in crystallite size is related to decrease in strain. The decrease in strain indicates the decrease in lattice imperfections, formation of high quality films and better crystallization of high quality $\mathrm{CuO}$ thin films. Furthermore, this can make $\mathrm{CuO}$ films, very interesting for photovoltaic applications [38].

\subsubsection{Optical Properties}

The optical transmittance spectra, recorded in the wavelength range from $300 \mathrm{~nm}$ to $1800 \mathrm{~nm}$ of copper oxide thin films prepared using different molar concentrations are shown in Figure 8. The films prepared from $0.1 \mathrm{M}$ showed a maximum transparency of $88 \%$ in the visible region. The spectra demonstrated a decreasing transparency from $88 \%$ to $60 \%$ by increasing the concentration from 0.1 to $0.5 \mathrm{M}$. Consequently, the decrease in optical transmittance with the increase in copper concentration can be attributed to the increase in films thicknesses. The average thickness of the obtained samples with different $\mathrm{Cu}$ concentration is presented in Table 2. It was observed that the average thickness increases with molar concentration from 133 to $253 \mathrm{~nm}$ as it is expected due to the increased quantity of $\mathrm{Cu}$ acetate used. For films with $0.3 \mathrm{M}$ and $0.5 \mathrm{M}$, the spectrum shows relatively high absorption in the region $(300-800 \mathrm{~nm})$ and lower absorbance in the NIR and IR regions.

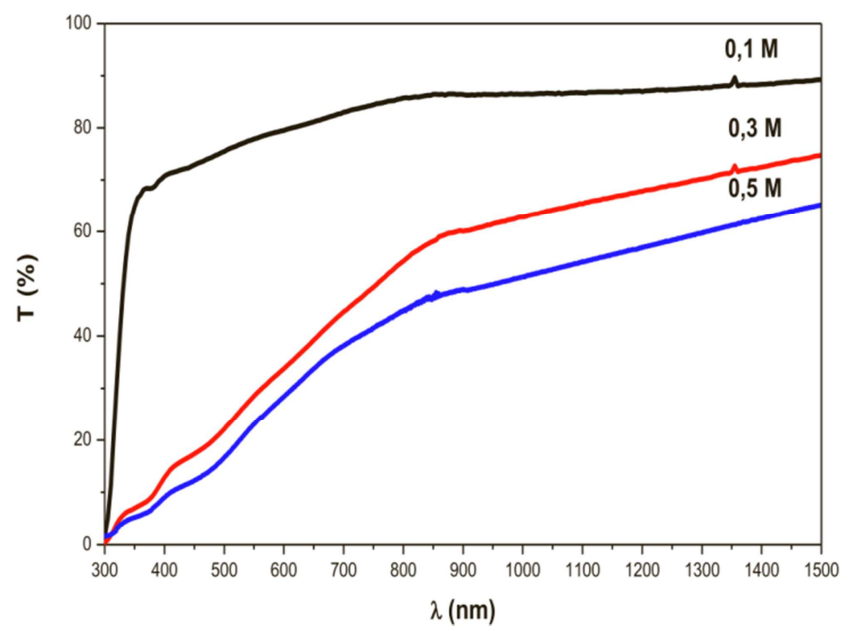

Figure 8. Transmittance spectra of thin films deposited using 0.1,0.3 and 0. 5 M precursor molar concentration.

Table 2. Values of average thickness and optical energy gap for various $C u$ molar concentration.

\begin{tabular}{lll}
\hline $\begin{array}{l}\text { Cu molar concentration } \\
\text { (M) }\end{array}$ & $\begin{array}{l}\text { Average thickness } \\
\text { (nm) }\end{array}$ & Energy gap (eV) \\
\hline 0.1 & 132 & 3.68 \\
0.3 & 175 & 2.56 \\
0.5 & 252 & 2.44 \\
\hline
\end{tabular}

The direct band gap of $\mathrm{CuO}$ films was determined from Tauc relation. The obtained results are presented in Table 2 . It was found that the band gap decreased from 3.68 to 2.44 $\mathrm{eV}$ with increase molar concentrations of $\mathrm{CuO}$ thin films. The $\mathrm{CuO}$ samples elaborated with $0.1 \mathrm{M}$ show higher direct band gap $(3.68 \mathrm{eV})$, reported by [3], as compared to bulk value $(1.3 \mathrm{eV}-2.1 \mathrm{eV})$ [2]. The decrease in band-gap may be attributed to the increase in films thicknesses of Copper oxide [43].

Therefore, it is clear for the sample elaborated with $0.5 \mathrm{M}$, a strong absorption observed at lower wavelengths and low band gap energy is obtained (about $2.44 \mathrm{eV}$ ). Hence these films have potential for the application of the films as absorber layer in solar cell fabrication [44].

\subsubsection{Electrical Properties}

The electrical resistivity was measured by the Van der Pauw method [28] in four-point configuration its dependence with the molar concentration is shown in Figure 9. The resistivity value increases slightly from $84 \Omega \mathrm{cm}$ to $124 \Omega \mathrm{cm}$ with the molar concentration. The raise of the crystallite size leads to an increase in the grain boundaries density. The increase of the electrical resistivity with the increase of crystallite size indicates that the conduction mechanism is driven by grain boundary scattering. Similar results, in the range $37.83-119.24 \Omega \mathrm{cm}$, are reported by K. S. Wanjala et al. [44].

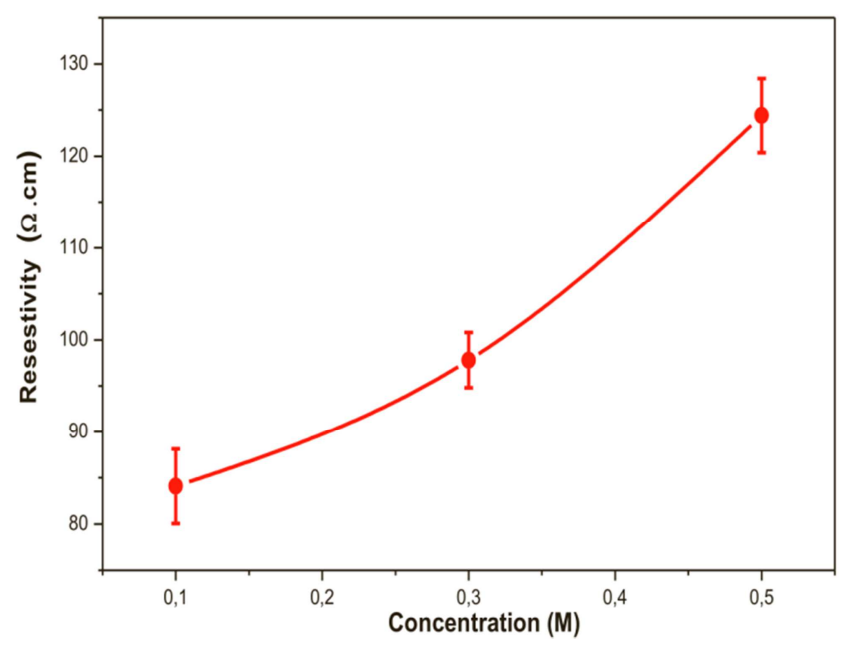

Figure 9. Electrical resistivity for $\mathrm{CuO}$ thin films as a function of different precursor molar concentration.

\section{Conclusions}

We have studied the effect of both annealing temperature and molar concentration on physical properties of $\mathrm{CuO}$ thin films deposited on glass substrates by a sol-gel spin-coating method. The best crystallinity and higher absorbance were found for films annealed at $550^{\circ} \mathrm{C}$. The optical band gap of $\mathrm{CuO}$ thin films decrease to $2.44 \mathrm{eV}$ after annealing at $550^{\circ} \mathrm{C}$. From the investigation of molar concentration, XRD analysis indicates that all deposited film are polycrystalline in nature with monoclinic structure The decrease in optical transmittance with 
the increase of molar concentration was attributed to the increase of the film thicknesses. We can notice that $\mathrm{CuO}$ film exhibit high absorption in the visible spectrum. This behaviour is very interesting for the use of $\mathrm{CuO}$ as an absorber layers in solar cells. The electrical resistivity increases with molar concentration, ranging between $84 \Omega \mathrm{cm}$ to $124 \Omega \mathrm{cm}$.

These results show that $\mathrm{CuO}$ films prepared by sol-gel spin-coating method can be used for preparation of solar cells $[38,43]$. These films can be prepared at relative low temperatures of $550^{\circ} \mathrm{C}$ showing good crystallinity with preferred orientation at (002) and (111) diffraction planes. Moreover we can start from relative high concentrations $(0.5$ M) to achieve thicker films with better properties. We intend to proceed by doping the $\mathrm{CuO}$ films with metals, to obtain films with lower resistivity.

\section{Acknowledgements}

Part of this work has been done at National Hellenic Research Foundation, Theoretical and Physical Chemistry Institute, 48 Vasileos Konstantinou Ave., 11635 Athens, Greece and financed by the Tunisian Ministry of Higher Education and Scientific. We thank Mr. Dimitrios Palles for the assistance in Raman data acquisition.

\section{References}

[1] F. Marabelli, G. B. Parravicini, F. Salghetti-Drioli (1995) Optical gap of CuO. Physical, Review B 52: 1433-1436.

[2] Wei-Tang Yao, Shu-Hong Yu, etc (2005) Formation of uniform $\mathrm{CuO}$ nanorods by spontaneous aggregation: selective synthesis of $\mathrm{CuO}, \mathrm{Cu} 2 \mathrm{O}$, and $\mathrm{Cu}$ nanoparticles by a solidliquid phase are discharge process, The Journal of Physical Chemistry B: 109: 14011-14016.

[3] F. Marabelli, G. B. Parravicini (1994) Evidence of localized states in the optical gap of CuO, Physica B 199-200: 255-256.

[4] Cyrus Wadia, A. Paul Alivisatos, Duniel M. Kammen (2009) Materials availability expands the opportunity for large-scale photovoltaics deployment, Environmental Science \& Technology 43: 2070-2077.

[5] Gavin Conibeer. (2007) Third-generation photovolatics, Materials Today 10: 42-50.

[6] N. López, L. A. Reichertz, K. M. Yu, K. Campman, W. Walukiewicz (2011) Band structure for multiband solar cells, Physical Review Letters 106: 028701.

[7] A. Polman, H. A. Atwater (2012) Nat. Mater. 11: 174.

[8] L. Zhu, G. Shao, J. K. Luo, (2011) Semicond. Sci. Tech. 26: 085026 .

[9] L. A. Patil, D. R. Patil (2006) Heterocontact type CuOmodified $\mathrm{SnO}_{2}$ sensor for the detection of a ppm level $\mathrm{H}_{2} \mathrm{~S}$ gas at room temperature, Sensors \& Actuators B: Chemical 120: 316-323.

[10] YunZhe Feng, Xiaolin Zheng (2010) Plasma-enhanced catalytic $\mathrm{CuO}$ nanowires for $\mathrm{CO}$ oxidation, Nano Letters 10: 4762-4766.
[11] C. C. Chusuei, M. A. Brookshier, D. W. Goodman (1999) Correlation of relative X-ray photoelectron spectroscopy shake-up intensity with $\mathrm{CuO}$ particle size, Langmuir 15: 28062808 .

[12] Jiatao Zhang, Junfeng Liu, et al (2006) Nearly monodisperse $\mathrm{Cu} 2 \mathrm{O}$ and $\mathrm{CuO}$ nanospheres: Preparation and Application for sensitive gas sensors, Chemistry of Materials 18: 867-871.

[13] P. Raksa, S. Nilphai, A. Gardchareon, S. Choopun (2009) Copper oxide thin films and nanowire as a barrier in $\mathrm{ZnO}$ dyesensitized solar cells, Thin Solid Films 517: 4741-4744.

[14] Fei Gao, Xiao-Jing Liu, Jun-Shan Zhang, Mei-Zhou Song, Ning Li (2012) Photovoltaic properties of the $\mathrm{p}-\mathrm{CuO} / \mathrm{n}-\mathrm{Si}$ heterojunction prepared through reactive magnetron sputtering, Journal of Applied Physics 111: 084507.

[15] Sang-Yun Sung, Se-Yun Kim, Kwang-Min Jo, Joon-Hyung Lee, Jeong-Joo Kim, Sang-Gon Kim, Kyoung-Hoon Chai, S. J. Pearton, D. P. Norton, YoungWoo Heo (2010) Fabrication of p-channel thin-film transistors using $\mathrm{CuO}$ active layers deposited at low temperature, Applied Physics Letters 97: 222109.

[16] C. Díaz-Guerra, M. vila, J. Piqueras (2010) Exchange bias in single-crystalline $\mathrm{CuO}$ nanowires, Applied Physics Letters 96: 193105 .

[17] A. Chen, H. Long, X. Li, Y. Li, G. Yang, P. Lu, (2009) Controlled growth and characteristics of single-phase $\mathrm{Cu}_{2} \mathrm{O}$ and $\mathrm{CuO}$ films by pulsed laser deposition, Vacuum 38: 927930.

[18] Hiroki Kidowaki, Takeo Oku, Tsuyoshi Akiyama, Atsushi Suzuki (2012) Fabrication and Characterization of CuO-based Solar Cells, Journal of Materials Science Research January, Vol. 1, No. 1.

[19] Fei Gao, Xiao-Jing Liu, Jun-Shan Zhang, Mei-Zhou Song, and Ning Li (2012) Photovoltaic properties of the p-CuO/n-Si heterojunction prepared through reactive magnetron sputtering, Journal of applied physics 111: 084507.

[20] A. Zainelabdin, S. Zaman, G. Amin, O. Nur, M. Willander (2012) Optical and current transport properties of $\mathrm{CuO} / \mathrm{ZnO}$ nanocoral $\mathrm{p}-\mathrm{n}$ heterostructure hydrothermally synthesized at low temperature, Appl. Phys. A: 108, 921.

[21] L. Liu, K. Hong, X. Ge, M. Xu, (2014) Aligned CuO nanorod arrays: fabrication and anisotropic ferromagnetism, Appl. Phys. A: 115-1147.

[22] L. Armelao, D. Barreca, M. Bertapelle, G. Bottaro, C. Sada, E. Tondello (2003) A sol-gel approach to nanophasic copper oxide thin films, Thin Solid Films: 442-4852.

[23] W. Wang, Z. Liu, Y. Liu, C. Xu, C. C. Zheng, G. Wang (2003) A simple wet-chemical synthesis and characterization of $\mathrm{CuO}$ nanorods, Appl. Phys. A: 76-417.

[24] V. F. Drobny, D. L. Pulfrey (1979) Properties of reactivelysputtered copper oxide thin films, Thin Solid Films 61: 8998.

[25] K. P. Muthe, J. C. Vyas, Savita N. Narang, D. K. Aswal, S. K. Gupta, Debarati Bhattacharya, R. Pinto, G. P. Kothiyal, S. C. Sabharwal (1998) A study of the $\mathrm{CuO}$ phase formation during thin film deposition by molecular beam epitaxy, Thin Solid Films 324: 37-43. 
[26] N. Mukherjee, B. Show, S. K. MAji, U. Madhu, S. K. Bhar, B. C. Mitra, G. G. Khan, A. Mondal (2011). CuO nano-whiskers: electrodeposition, Raman analysis, photoluminescence study and photocatalytic activity, Mater. Letters 65: 3248-3250.

[27] A. A. Al-Ghamdi, Waleed E. Mahmoud, S. J. Yaghmour, F. M. Al- Marzouki (2009) Structure and optical properties of nanocrystalline $\mathrm{NiO}$ thin film synthesized by sol-gel spincoating method, J. Alloys Compd 486: 9-13.

[28] L. J Van der Pauw (1958) A method of measuring specific resistivity and Hall effect of discs of arbitrary shape, Philips Res Repts, 13: 1-9.

[29] C. S. Garrett, T. B. Massalski (1980) Structure of Metals, Pergamon Press, Oxford.

[30] Dattarya Jundale, Shailesh Pawar, Manik Chougule, Prasad Godse, Sanjay Patil Bharat Raut, Shashwati Sen, Vikas Patil (2011) Nanocrystalline $\mathrm{CuO}$ Thin Films for $\mathrm{H}_{2} \mathrm{~S}$ Monitoring, Microstructural and Optoelectronic Characterization, Journal of Sensor Technology 1: 36-46 doi:10.4236/jst.2011.12006 Published Online June 2011.

[31] B. D. Cullity, S. R. Stock, Elements of X-Ray Diffraction (2001), 3rd ed., Prentice Hall, Upper Saddle River, New Jersey.

[32] Shou-Yi Kuo, Wei-Chun Chen, Chin-Pao Cheng (2006) Investigation of annealing-treatment on the optical and electrical properties of sol-gel-derived zinc oxide thin films, Superlattices and Microstructures 39: 162-170.

[33] Z. Ghorannevis, M. T. Hosseinnejad, M. Habibi, P. Golmahdi (2015) Effect of substrate temperature on structural, morphological and optical properties of deposited $\mathrm{Al} / \mathrm{ZnO}$ films, J Theor Appl Phys 9: 33-38 DOI 10.1007/s40094-0140157-1.

[34] Yunus Akaltun (2015) Effect of thickness on the structural and optical properties of $\mathrm{CuO}$ thin films grown by successive ionic layer adsorption and reaction, Thin Solid Films, Volume 594, Part A, Pages 30-34 doi: 10.1016/j.tsf.2015.10.003.
[35] Kliche, G.; Popovic, Z. V. Far-infrared spectroscopic investigations on CuO, Phys. Rev. B (1990), 42, 10060-10066.

[36] HF Goldstein, Kim D, Yu PY, Bourne LC (1990) Raman study of $\mathrm{CuO}$ single crystals, Phys Rev B 41: 7192.

[37] P. K. Ooi, S. S. Ng, M. J. Abdullah, H. Abu Hassan, Z. Hassan (2013) Effects of oxygen percentage on the growth of copper oxide thin films by reactive radio frequency sputtering, Materials Chemistry and Physics 140 (1): 243-248.

[38] R. Shabu, A. Moses Ezhil Raj, C. Sanjeeviraja, C. Ravidhas (2015) Assessment of $\mathrm{CuO}$ thin films for its suitablity as window absorbing layer in solar cell fabrications, Materials Research Bulletin 68: 1-8.

[39] S. Karthick Kumar, S. Suresh, S. Murugesan, Samuel Paul Raj (2013) $\mathrm{CuO}$ thin films made of nanofibers for solar selective absorber applications, Solar Energy. 94: 299-304.

[40] J. Tauc (Ed), Amorphous \& Liquid Semi-conductors (1974), Plenum Press, New York, NY.

[41] G. Papadimitropoulos, N. Vourdas, V. Em. Vamvakas, D. Davazoglou (2005) Deposition and characterization of copper oxide thin films, Journal of Physics: Conference Series 10: 182-185, doi:10.1088/1742-6596/10/1/045.

[42] Addison. (1956) Wesley Publishills Ca., Inc. Reading, Mass.

[43] A. Ashour, M. A. Kaid, N. Z. El-Sayed and A. A. Ibrahim (2006) Physical properties of $\mathrm{ZnO}$ thin films deposited by spray pyrolysis technique, Applied Surface Science 252: 7844-7848.

[44] K. S. Wanjala, W. K. Njoroge, N. E. Makori, J. M. Ngaruiya (2016) Optical and Electrical Characterization of $\mathrm{CuO}$ Thin Films as Absorber Material for Solar Cell Applications, American Journal of Condensed Matter Physics 6 (1): 1-6. 